\title{
The role of FAS gene variants in inflammatory bowel disease
}

\author{
Ayhan Demir $^{1}$ (D), Resul Kahraman² (D), Gonca Candan ${ }^{1}$ (D), Arzu Ergen ${ }^{1}$ (D) \\ ${ }^{1}$ Department of Molecular Medicine, Istanbul University, Aziz Sancar Institute of Experimental Medicine, Istanbul, Turkey \\ ${ }^{2}$ Department of Gastroenterology, Ümraniye Training and Research Hospital, Istanbul, Turkey
}

Cite this article as: Demir A, Kahraman R, Candan G, Ergen A. The role of FAS gene variants in inflammatory bowel disease. Turk J Gastroenterol 2020; 5: 356-61.

\begin{abstract}
Background/Aims: The analysis of genes thought to be important in inflammatory bowel disease (IBD) has shown that more than half of IBD-related genes are also associated with other autoimmune diseases. The aim of this study was to detect a possible association between the polymorphisms of the $(-670 \mathrm{~A} / \mathrm{G},-1377 \mathrm{G} / \mathrm{A})$ fFas cell surface death receptor (FAS) gene promoter and susceptibility to IBD in the Turkish population.

Materials and Methods: In total, 125 patients with IBD, including 73 ulcerative colitis and 52 Crohn's disease and also 101 healthy controls without any pathological signs of IBD were considered for the study. Real-time polymerase chain reaction technique was used to detect FAS polymorphisms in this study.

Results: The analysis of FAS -670 A/G polymorphism indicated that the frequency of GG genotype was significantly increased in patients compared with controls $(p<0.001)$. Additionally, AG genotype $(p<0.001)$ and A allele $(p<0.001)$ frequencies were higher in controls than in patients. The analysis of FAS $-1377 \mathrm{G} / \mathrm{A}$ polymorphism revealed that the frequency of AA genotype was meaningfully increased in patients compared with controls $(p<0.001)$. Additionally, GG genotype $(p<0.001)$ and G allele $(p<0.001)$ frequencies were increased in controls when compared with patients.

Conclusion: FAS -670A/G GG genotype seemed to be a protective allele against IBD; however, AA genotype and A allele were associated with elevated risk of IBD. In the FAS -1377G/A polymorphism, frequencies of the G allele and GG genotype were observed to be protective against IBD, whereas $A A$, GA genotypes, and A allele frequency increased in the patient group.

Keywords: FAS receptor, single nucleotide polymorphism, inflammatory bowel diseases
\end{abstract}

\section{INTRODUCTION}

Inflammatory Bowel Disease (IBD) is a chronic, autoimmune disease that affects the intestines and has unknown etiology. Inflammatory bowel disease (IBD causes inflammation in genetically susceptible individuals by developing an immune response to the intestinal microbiota or environmental antigens (1). IBD includes ulcerative colitis $(\mathrm{UC})$, Crohn's disease (CD), and unspecified bowel disease (UBS), formerly called indeterminate colitis. The term UBS is used when there is no differential diagnosis between UC and $C D(2,3)$. This can be distinguished by genetic susceptibility, risk factors, and differences in clinical, endoscopic, and histological characteristics (4). Environmental factors are thought to play a strong role in mediating IBD risk, but a single environmental factor has not been proven to have a definite causal function (5). Although the etiology of IBS is not fully known, it is thought that genetically susceptible individuals cause inflammation with an uncontrolled immune response in the intestinal lumen as a result of a combination of environmental and immunological factors.
Apoptosis of intestinal epithelial cells (IECs) and intestinal lamina propria cells causes an impaired mucosal immune response and tissue inflammation.

More than 200 risky gene regions believed to be associated with IBS are described by the genome-wide association studies study, which covers approximately $100,000 \mathrm{pa}-$ tients (6). Despite different clinical features, some genetic loci related to IBD are common in CD and UC diseases (7, 8). The analysis of genes thought to be important in IBD has shown that barrier function, microbial defense, regeneration of epithelium, regulation of natural immunity, production of reactive oxygen species (ROS), autophagy, regulation of acquired immunity, and endoplasmic reticulum stress are important for intestinal homeostasis $(6,9)$. It has been shown that more than half of IBD-related genes are also associated with other autoimmune diseases (10).

Members of the tumor necrosis factor (TNF) superfamily (TNFSF) affect the pathogenesis of IBS in two ways. First,

This study was presented at the 28. National Biochemistry Congress, 19-23 September 2017, Erzurum, Turkey. 
they affect the regulation of the adhesion proteins of the intestinal cells (TNFs) and disrupt the intestinal epithelial structure of the intestinal cells by dragging the apoptosis (TNF, FAS ligand [FasL], TNF-associated apoptosis-inducing ligand [TRAIL], and TNF-like weak inducer of apoptosis (TWEAK)). Second, the inflammatory effects of leucocytes passing through the mucosa are revealed (TNF, Tumor necrosis factor (TNF)-like cytokine 1A (TL1A), TNF superfamily member 14 (TNFSF14) TWEAK and possibly FasL) (11). The FAS receptor (FASR), also known as the First Apoptosis Signal Receptor (FAS, FASR), the cluster of differentiation 95 (CD95) or the TNF receptor superfamily member 6 , is a protein encoded by the FAS gene in humans $(12,13)$. The FASR is a death receptor that causes programmed cell death (apoptosis) at the surface of the cell. It is one of two apoptosis pathways, the other is a mitochondrial pathway (14). FAS is 25,255 bases in length, which is localized in the long arm of chromosome 10 (10q24.1) in humans and consists of nine exons and eight introns (15).

Studies reported that the promoter region of the FAS gene includes two polymorphisms. First one is a single nucleotide substitution $(A / G)$ at the -670 position, whereas another one is at the -1377 position (G/A) (16). Although FAS (CD95) is known to be an apoptosis-inducing death receptor, studies have shown that the FAS-FasL system stimulates the production of proinflammatory cytokines by macrophages (16-18). One of the FAS/Apo-1 gene polymorphisms, $-670 \mathrm{~A} / \mathrm{G}$ single nucleotide substitution, has been shown to be associated with many autoimmune diseases. This polymorphism is thought to be one of the causes of IBD (19-23).

Genetic studies related to FAS gene and IBS have been conducted in different human populations. The study by Bing Xia et al. was carried out using 50 patients with IBD (38 UC and 12 CD) and 124 healthy controls and genotyped for FAS- 670 polymorphism by PCR method. FAS670 polymorphism in Chinese patients has not been associated with IBD (24). In the study, 105 patients with CD, 59 patients with UC, and 100 healthy controls were analyzed to examine FAS $-670 \mathrm{~A} / \mathrm{G}$ polymorphism by the polymerase chain reaction method in Tunisian population by Ben Aleya et al. (19). In conclusion, FAS-670 polymorphism in the Tunisian population was found to be associated with $\mathrm{CD}$ and $\mathrm{UC}$. There is no study that has examined the relationship of FAS $-1377 \mathrm{G} / \mathrm{A}$ polymorphism with IBD.

Many studies have used anti-TNF therapy in the treatment of IBS such as UC and CD, and the treatment re- sponse of individuals with FAS polymorphism has been examined and significant results have been obtained (17, 25). The aim of this study was to investigate the possible effects of FAS -670A/G (rs1800682) and -1377G/A (rs2234767) gene polymorphisms in IBS with clinical and prognostic parameters in our study.

\section{MATERIALS AND METHODS}

\section{Patients}

In this study, 125 patients that were diagnosed with UC (73 patients) and CD (52 patients), and 101 healthy control groups without any pathological signs of disease were considered. The disease group samples were obtained from the hospital. Written informed consent was obtained from patients and healthy controls who participated in this study. Blood samples were collected subsequent to ethical committee (Medical Ethics Committee of Istanbul Medical Faculty, 1752/2015) approval. Clinical evaluations of the patient group used in this study were carried out in the hospital and the collection of blood samples was performed by the hospital. Blood samples of patients and healthy control subjects were collected in tubes containing Ethylenediamine Tetra Acetate. After DNA isolations (Invitrogen PureLink Genomic DNA kit, Thermo Fisher Scientific, USA) of 125 patients with IBS and 101 healthy control groups were performed, the analysis of the FAS gene variants was performed.

\section{Methods}

TaqMan Single Nucleotide Polymorphism (SNP) Genotyping Assays (Applied Biosystems, USA) consist of a TaqMan minor groove binder (MGB) probe containing two different fluorescent reporter dyes (VIC and FAM) specific for ancestral and mutant alleles, and a pair of PCR primers to detect the specific SNP target. The TaqMan 2× Universal PCR Master Mix (Applied Biosystems, USA) contains AmpliTaq Gold DNA Polymerase, dNTPs including dUTP, AmpErase UNG, Passive reference dye (ROX), and optimized buffer components. For patient and control studies, $1.5 \mathrm{~mL}$ tubes on the ice were supplemented with $8 \mu \mathrm{L}$ distilled water, $10 \mu \mathrm{L}$ Master mix, and $0.5 \mu \mathrm{L}$ 40X Genotyping Assay pipetting in a sterile environment. This obtained PCR mixture was distributed as $18.5 \mu \mathrm{L}$ in 96 well plate wells for each sample and $1.5 \mu \mathrm{L}$ DNA was pipetted into each well. Eventually, each well reached a total reaction volume of $20 \mu \mathrm{L}$. One of the real-time PCR instruments (Applied Biosystems 7500 Fast Instrument or Applied Biosystems StepOnePlus Instrument, USA) was preset to $60^{\circ} \mathrm{C}$ according to the amplification conditions to which the PCR mixture and DNA were added to 
96 well plate and the PCR process started. Real-time PCR was performed as follows: initial denaturation at $95^{\circ} \mathrm{C}$ for $10 \mathrm{~min}$, followed by 40 amplification cycles, each consisting of denaturation at $95^{\circ} \mathrm{C}$ for $30 \mathrm{~s}$, annealing/extension at $60^{\circ} \mathrm{C}$ for $1 \mathrm{~min}$, and final step at $60^{\circ} \mathrm{C}$ for $1 \mathrm{~min}$. Variants were analyzed by fluorescence analysis of FAM- and VIC-labeled probes.

\section{Statistical Analysis}

Statistical analysis of this study was performed using the SPSS Statistics 21.0 package program (Chicago, IL, USA) and the statistical significance limit was accepted as $p<0.05$. Differences in frequency of genotypes and alleles among the groups were evaluated using $x 2$ and Fisher Exact test. The frequencies of alleles were determined according to the gene counting method. Students' $t$, oneway Analysis of Variance (ANOVA), and Mann Whitney U tests were used to compare demographic data between groups.

\section{RESULTS}

The study group included 73 patients with UC, 52 patients with CD, and 101 healthy people with no IBS as a control group. Biochemical and demographic information of our study groups is given in Table 1. There was no statistically significant difference between the patient and

Table 1. Biochemical and demographic parameters of the study groups.

\begin{tabular}{|c|c|c|}
\hline Biochemical parameters & Patients $(n=125)$ & Control $(n=101)$ \\
\hline Age & $43.06 \pm 13.50$ & $44.45 \pm 13.99$ \\
\hline \multicolumn{3}{|l|}{ Gender } \\
\hline Male & 64 & 50 \\
\hline Female & 61 & 51 \\
\hline C-Reactive Protein (mg/L) & $1.01 \pm 2.64$ & $0.49 \pm 1.17$ \\
\hline Sedimentation & $26.33 \pm 19.99$ & $28.80 \pm 11.43$ \\
\hline Demographic parameters & UC Patients $(n=73)$ & Crohn Patients $(n=52)$ \\
\hline \multicolumn{3}{|l|}{ UC involvement } \\
\hline Proctitis (n/\%) & $33 / 45.8$ & - \\
\hline Left Colon (n/\%) & $18 / 25$ & - \\
\hline Extensive $(n / \%)$ & $21 / 29.2$ & - \\
\hline \multicolumn{3}{|l|}{ CD involvement } \\
\hline Ileal (n/\%) & - & $23 / 44.2$ \\
\hline Ileocolonic (n/\%) & - & $24 / 46.2$ \\
\hline Colonic $(n / \%)$ & - & $5 / 9.6$ \\
\hline \multicolumn{3}{|l|}{ CD type } \\
\hline Inflammatory (n/\%) & - & $26 / 51$ \\
\hline Fistulization (n/\%) & - & $10 / 19.6$ \\
\hline Stricturation (n/\%) & - & $14 / 27.5$ \\
\hline Fistulization and Stricturation $(\mathrm{n} / \%)$ & - & $1 / 2$ \\
\hline \multicolumn{3}{|l|}{ Degree of disease } \\
\hline $\operatorname{Mild}(\mathrm{n} / \%)$ & $42 / 57.5$ & $18 / 35.5$ \\
\hline Moderate $(n / \%)$ & $27 / 37$ & $24 / 47.1$ \\
\hline Severe $(n / \%)$ & $4 / 5.5$ & $9 / 17.6$ \\
\hline Mesalazine usage $(n / \%)$ & - & $45 / 86.5$ \\
\hline Steroid usage $(\mathrm{n} / \%)$ & - & $6 / 11.5$ \\
\hline Azidothymidinesage $(n / \%)$ & - & $37 / 71.2$ \\
\hline TNF usage $(n / \%)$ & - & $19 / 36.5$ \\
\hline
\end{tabular}

$\mathrm{n}=$ number of people; group differences were examined by $\mathrm{X} 2$ and student t test. UC: Ulcerative Colitis; CD: Crohn's disease; TNF: tumor necrosis factor. 
control groups in the statistical analysis $(p>0,05)$. There was no difference in biochemical parameters between patients and control group.

When the genotype and allele distributions of FAS -670 $A / G$ polymorphism were examined between the study groups, GG genotype $(p<0.001, x 2=21.45, O R=3.98$, $95 \%$ confidence interval=2.18-7.27) was found to be statistically higher than the control group. In the control group, AG genotype $(p<0.001, x 2=13.11, O R=1.8,95 \%$ confidence interval $=1.30-2.54)$ and $A$ allele $(p<0.001$, $X 2=21.45, O R=1.59,95 \%$ confidence interval $=1.30-1.94$ ), the frequency showed a statistically significant increase over the patient group. When we compared the groups in terms of FAS $-1377 \mathrm{G} / \mathrm{A}$ polymorphism, GG genotype $(p<0.001, \chi 2=92.90, O R=10.52,95 \%$ confidence inter$v a l=5.30-20.84)$ and $G$ allele $(p<95$ confidence inter$\mathrm{val}=1.20-1.53$ ) showed a statistically significant increase

Table 2. Genotype and allele distributions for FAS -670 A/G and $1377 \mathrm{G} / \mathrm{A}$ polymorphisms in study groups.

\begin{tabular}{|c|c|c|}
\hline $\begin{array}{l}\text { FAS }^{\mathrm{a}}-670 \mathrm{~A} / \mathrm{G} \\
\text { polymorphism }\end{array}$ & $\begin{array}{l}\text { Patients } \\
\left(n^{b}=125\right)\end{array}$ & $\begin{array}{l}\text { Control } \\
(n=101)\end{array}$ \\
\hline $\mathrm{AA},(\mathrm{n} / \%)$ & $27 / 21.6$ & $28 / 27.7$ \\
\hline$G G,(n / \%)$ & $62 / 49.6^{c}$ & $20 / 19.8$ \\
\hline$A G,(n / \%)$ & $36 / 28.8$ & $53 / 52.5^{*}$ \\
\hline $\mathrm{A},(\mathrm{n} / \%)$ & $90 / 36$ & $109 / 53.9^{*}$ \\
\hline$G,(n / \%)$ & $160 / 64$ & $93 / 46.1$ \\
\hline $\begin{array}{l}\text { FAS } 1377 \mathrm{G} / \mathrm{A} \\
\text { polymorphism }\end{array}$ & $\begin{array}{l}\text { Patients } \\
(n=125)\end{array}$ & $\begin{array}{l}\text { Control } \\
(n=101)\end{array}$ \\
\hline$G,(n / \%)$ & $8 / 6.4$ & $68 / 67.3^{*}$ \\
\hline $\mathrm{AA},(\mathrm{n} / \%)$ & $37 / 29.6^{*}$ & $4 / 4$ \\
\hline $\mathrm{GA},(\mathrm{n} / \%)$ & $80 / 64^{d}$ & $29 / 28.7$ \\
\hline $\mathrm{G},(\mathrm{n} / \%)$ & $96 / 38.4$ & $165 / 81.7^{*}$ \\
\hline$A,(n / \%)$ & $154 / 61.6^{*}$ & $37 / 18.3$ \\
\hline \multicolumn{3}{|c|}{$\begin{array}{l}\text { aFAS: first apoptosis signal. } \\
{ }^{b} n \text { : number of people. } \\
{ }^{c} p<0.001 . \\
\text { dtotal patient versus control group. }\end{array}$} \\
\hline
\end{tabular}

in the frequency compared with the patient group. On the other hand, AA genotypes $(p<0.001, \chi 2=27.85$, $\mathrm{OR}=4,41,95 \%$ confidence interval $=3.43-29.76 ; p<0.001$, $95 \%$ confidence interval $=2.50-7.76$ ) and $A$ allele $(p<0.001, x 2=92.90, O R=30.13,95 \%$ confidence interval=13.16-68.98) were observed to have increased frequency (Table 2).

In the linkage disequilibrium analyses, a weak association is determined between the FAS $-670 \mathrm{~A} / \mathrm{G}$ and $-1377 \mathrm{G} / \mathrm{A}$ alleles $\left(D^{\prime}=0.44, \mathrm{LOD}=7,6, \mathrm{r}^{2}=0.116\right.$; Table 3$)$.

\section{DISCUSSION}

IBDs, such as UC and CD, are chronic and autoimmune diseases affecting the intestines with unknown etiology. The resulting inflammation is prevented by the immune system, preventing damage to the intestines. In IBD patients, this inflammatory response cannot be prevented and becomes even more exaggerated. Although the etiology of IBD is not fully known, it is thought that genetically susceptible individuals cause inflammation with an uncontrolled immune response in the intestinal lumen as a result of a combination of environmental and immunological factors. Apoptosis of IECs and intestinal lamina propria cells causes an impaired mucosal immune response and tissue inflammation. Programmed cell death or apoptosis is controlled by intracellular signals that are tightly controlled in response to pathological cytotoxic stimuli including TNF-a, TRAIL, and FAS $(14,26)$. FAS, a member of the TNFSF, is expressed by the normal basolateral membrane and the small intestine. FAS ligation is caused by apoptosis in colonic epithelial cells and has been shown to be associated with epithelial damage seen in UC. FasL is expressed by intraepithelial and lamina propria lymphocytes, and expression is thought to be increased in the lamina propria of UC patients and contributes to the mucosal injury of FAS-FasL-induced apoptosis UC $(14,26)$. The role of FAS/FasL in UC is focused on the hypothesis that FAS-positive IECs result in the targeting of FasL-positive lymphocytes, ending with IEC

Table 3. Linkage disequilibrium.

\begin{tabular}{|c|c|c|c|c|}
\hline Haplotype Associations & Frequencies & Case, control ratios & Chi Square & $\mathrm{p}$ \\
\hline GA & 0.338 & $0.202 ; 0.506$ & 45.94 & $<0.001$ \\
\hline$A G$ & 0.320 & $0.458 ; 0.149$ & 49.06 & $<0.001$ \\
\hline GG & 0.240 & $0.148 ; 0.311$ & 10.29 & 0.001 \\
\hline AA & 0.103 & $0.158 ; 0.034$ & 18.57 & $<0.001$ \\
\hline
\end{tabular}


apoptosis. In the UC, apoptosis of IEC has been reported in crypts and it has been shown that FasL is upregulated on intestinal lymphocytes in UC. Although FAS/FasL-mediated apoptosis contributes to intestinal tissue damage, lamina propria lymphocytes are thought to be more important for sustaining chronic inflammation, probably due to apoptosis resistance $(27,29)$. Many studies have used anti-TNF therapy in the treatment of IBSs such as $U C$ and $C D$, and the treatment response of patients with FAS polymorphism has been examined and significant results have been obtained $(17,28)$.

In our study, we aimed to investigate the possible effects of FAS-670 A/G (rs1800682) and -1377 G/A (rs2234767) gene polymorphisms in IBS with clinical and prognostic parameters. A total of 125 individuals, 73 diagnosed with UC, 52 with $C D$, and 101 healthy controls with no pathological signs of disease were used. In previous studies, the association of FAS-670 A/G polymorphism with IBS has been studied in different country populations, but no study has examined the relationship between IBS polymorphism and $-1377 \mathrm{G} / \mathrm{A}$ polymorphism. In this study, patients and healthy subjects were evaluated for both polymorphisms. As a result of our experimental studies, we found that FAS -670 A/G A allele was protective against IBD in the group of patients, while GG genotype was associated with an increased risk of disease. In the FAS -1377 G/A polymorphism, $G$ allele and GG genotype were observed to be protective against IBD whereas the AA, GA genotypes, and $A$ allele frequency increased in the patient group.

In the study by Xia et al., it was found that FAS-670 polymorphism was not associated with IBD in Chinese patients (24). Additionally, in studies performed by researchers with patients in the Netherlands, Australia, and Korea, there was no correlation between FAS -670A/G polymorphism $(29,30)$. In total, 105 patients with $C D$, 59 patients with $U C$, and 100 healthy controls were analyzed to examine FAS $-670 \mathrm{~A} / \mathrm{G}$ polymorphism by the polymerase chain reaction method in Tunisian population by Ben Aleya et al. (19). They found that the frequencies of FAS-670A allele and AA homozygous individuals in CD and UC patients were significantly lower when compared with controls. The analysis of FAS polymorphism according to sex $(-670 \mathrm{~A} / \mathrm{G})$ in $\mathrm{CD}$ and $\mathrm{UC}$ revealed a significant difference in AA genotypes between female patients and controls. The analysis also showed a statistically significant relationship between $(-670 \mathrm{~A} / \mathrm{G})$ polymorphism in AA genotype and localization of ileal lesions, and between GG genotype and localization of colon lesions. The analysis of the clinical behavior of patients with IBD showed no difference. In conclusion, FAS-670 polymorphism in the Tunisian population has been found to be associated with CD and UC (19).

One of the limitations of this study is the relatively small size of the study population. Another limitation is that we could not use any other techniques, such as Enzyme linked immunosorbent assay (ELISA) for the determination of serum FAS levels, to support our results.

The studies carried out are the first to be performed in our country in terms of IBD cases with both polymorphisms ( -670 A/G and -1377 G/A). Moreover, FAS -1377 is one of the first studies in the international literature related to IBD for G/A polymorphism. The results suggest that FAS $-670 \mathrm{~A} / \mathrm{G}$ AA genotype and $\mathrm{A}$ allele and FAS $-1377 \mathrm{G} / \mathrm{A}$ carrying $\mathrm{A}$ allele were associated with elevated risk of IBD. We believe that the results of this study will be an important guide for future studies, especially in terms of being the first study of FAS $-1377 \mathrm{G} / \mathrm{A}$ polymorphism and showing high risk relationship between $-670 \mathrm{~A} / \mathrm{G}$ polymorphism and IBD.

Ethics Committee Approval: Ethics committee approval was received for this study from the Ethics Committee of İstanbul University, İstanbul School of Medicine (1752/2015).

Informed Consent: Written informed consent was obtained from patients who participated in this study.

Peer-review: Externally peer-reviewed.

Author Contributions: Concept - A.D., A.E.; Design - A.D., R.K.; Supervision - A.E. Resource - A.E.; Materials - R.K.; Data Collection and/ or Processing -G.C., A.D.; Analysis and/or Interpretation -A.E., A.D.; Literature Search - A.D., G.C.; Writing -A.D.; Critical Reviews - A.E.

Conflict of Interest: The authors have no conflicts of interest to declare.

Financial Disclosure: This work was supported by Scientific Research Projects Coordination Unit of Istanbul University. Project number: 20728.

\section{REFERENCES}

1. Abraham J, Cho JH. Inflammatory Bowel Disease. N Engl J Med 2009; 19: 2066-78. [Crossref]

2. Geboes K, Van Eyken P. Inflammatory bowel disease unclassified and in determinate colitis: the role of the pathologist. J Clin Pathol 2009; 62: 201-5. [Crossref]

3. Magro F, Langner C, Driessen A, et al. European consensus on the histopathology of inflammatory bowel disease. J Crohns Colitis 2013; 7: 827-51. [Crossref]

4. Ordás I, Mould DR, Feagan BG, Sandborn WJ. Anti-TNF monoclonal antibodies in inflammatory bowel disease: pharmacokinetics-based dosing paradigms. Clin Pharmacol Ther 2012; 91: 635-46. [Crossref] 
5. Bernstein CN. Treatment of IBD: where we are and where we are going. Am J Gastroenterol 2015; 110: 114-26. [Crossref]

6. de Lange KM, Moutsianas L, Lee JC, et al. Genome-wide association study implicates immune activation of multiple integrin genes in inflammatory bowel disease. Nat Genet 2017; 49: 256-61. [Crossref]

7. Liu JZ, van Sommeren S, Huang $H$, et al. Association analyses identify 38 susceptibility loci for inflammatory bowel disease and highlight shared genetic risk across populations. Nat Genet 2015; 47: 979-86. [Crossref]

8. Jostins L, Ripke S, Weersma RK, et al. Host-microbe interactions have shaped the genetic architecture of inflammatory bowel disease. Nature 2012; 491: 119-24. [Crossref]

9. Barrett JC, Hansoul S, Nicolae DL, et al. Genome-wide association defines more than 30 distinct susceptibility loci for Crohn's disease. Nat Genet 2008; 40: 955-62. [Crossref]

10. Parkes M, Cortes A, van Heel DA, Brown MA. Genetic insights into common pathways and complex relationships among immune-mediated diseases. Nat Rev Genet 2013; 14: 661-73. [Crossref]

11. Tavares $M$, de Lima $C$, Fernandes $W$, et al. Tumour necrosis factor-alpha $(-308 \mathrm{G} / \mathrm{A})$ promoter polymorphism is associated with ulcerative colitis in Brazilian patients. Int J Immunogenet 2016; 43: 376-82. [Crossref]

12. Lichter $P$, Walczak $H$, Weitz $S$, Behrmann I, Krammer PH. The hu-man APO-1 (APT) antigen maps to 10q23, a region that is syntenic with mouse chromosome 19. Genomics 1992; 14: 179-80. [Crossref]

13. Wajant $H$. The Fas signaling pathway: more than a paradigm. Science 2002; 31: 1635-6. [Crossref]

14. Inazawa J, Itoh N, Abe T, Nagata S. Assignment of the human Fas antigen gene (Fas) to 10q24.1. Genomics 1992; 14: 821-2. [Crossref] 15. Ma Y, Liu H, Tu-Rapp H, et al. Fas ligation on macrophages enhances IL-1R1-Toll-like receptor 4 signaling and promotes chronic inflammation. Nat Immunol 2004; 5: 380-7. [Crossref]

16. Ślebioda TJ, Kmieć Z. Tumour necrosis factor superfamily members in the pathogenesis of inflammatory bowel disease. Mediators Inflamm 2004; 2014: 325129. [Crossref]

17. Steenholdt C, Enevold C, Ainsworth MA, Brynskov J, Thomsen $O \varnothing$ Bendtzen K. Genetic polymorphisms of tumour necrosis factor receptor superfamily $1 \mathrm{~b}$ and fas ligand are associated with clinical efficacy and/or acute severe infusion reactions to infliximab in Crohn's disease. Aliment Pharmacol Ther 2012; 36: 650-9. [Crossref]
18. Ng SC, Tang W, Ching JY, et al. Incidence and phenotype of inflammatory bowel disease based on results from the Asia-pacific Crohn's and colitis epidemiology study. Gastroenterology 2013; 145: 158-65. [Crossref]

19. Ben Aleya W, Sfar I, Mouelhi L, et al. Association of Fas/Apo1 gene promoter (-670 A/G) polymorphism in Tunisian patients with IBD. World J Gastroenterol 2009; 7: 3643-8. [Crossref]

20. Thesis: Fernandes $P$. Characterisation of the role of Fas in intestinal inflammation and cancer. University College Cork. PhD Thesis, 2015.

21. Kokkonen TS, Karttunen TJ. Endothelial Fas-Ligand in Inflammatory Bowel. Diseases and in Acute Appendicitis. J Histochem Cytochem 2015; 63: 931-42. [Crossref]

22. Pinkoski MJ, Brunner T, Green DR, Lin T. Fas and Fas ligand in gut and liver. Am J Physiol Gastrointest Liver Physiol 2000; 278: 354-66. [Crossref]

23. Bechmann I, Mor G, Nilsen J, Eliza M, Nitsch R, Naftolin F. FasL (CD95L, Apo1L) is expressed in the normal rat and human brain: evidence for the existence of an immunological brain barrier. Glia 1999; 27: 62-74.

24. Xia B, Yu YH, Guo QS, Li XY, Jiang L, Li J. Association of Fas-670 gene polymorphism with inflammatory bowel disease in Chinese patients. World J Gastroenterol 2005; 21: 415-7. [Crossref]

25. Cravo M, Ferreira P, Sousa P, Moura-Santos P, Velho S, Tavares $L$, et al. Clinical and genetic factors predicting response to therapy in patients with Crohn's disease. United European Gastroenterol J 2014; 2: 47-56. [Crossref]

26. Huang QR, Morris D, Manolios N. Identification and characterization of polymorphisms in the promoter region of the human Apo-1/ Fas (CD95) gene. Mol Immunol 1997; 34: 577-82. [Crossref]

27. Ueyama H, Kiyohara T, Sawada N, et al. High Fas ligand expression on lymphocytes in lesions of ulcerative colitis. Gut 1998; 43: 4855. [Crossref]

28. Levine $A D$, Fiocchi $C$. Regulation of life and death in lamina propria T cells. Semin Immunol 2001; 13: 195-9. [Crossref]

29. Satsangi J, Morecroft J, Shah NB, Nimmo E. Genetics of inflammatory bowel disease: scientific and clinical implications. Best Pract Res Clin Gastroenterol 2003; 17: 3-18. [Crossref]

30. Gaya DR, Russell RK, Nimmo ER, Satsangi J. New genes in inflammatory bowel disease: lessons for complex diseases? Lancet 2006; 15: 1271-84. [Crossref] 